\title{
La imaginación: el principio, medio y fin del estado de naturaleza hobbesiano
}

Christian David Núñez Prado

Universidad del Valle, Colombia 


\title{
La imaginación: el principio, medio y fin del estado de naturaleza hobbesiano*
}

\begin{abstract}
Resumen: en este artículo la imaginación es el concepto clave para identificar la evolución epistemológica del hombre natural. A través de la primacía del sentimiento de placer se va a exponer, en tres momentos, el desarrollo de las facultades mentales en donde, primero, predomina una imaginación pictórica individual que refiere el placer a los objetos de la sensibilidad y utiliza la razón calculadora para asegurárselos de forma continua. Segundo, su paso hacia una imaginación pictórica mediada por un poder capaz de reunir a los hombres e imponerse, que refiere el placer hacia una realidad de signos y comportamientos comunes. Por último, la inmediatez del sentimiento de placer de la imaginación pictórica es subordinada al placer derivado de la creación de símbolos significativos lingüísticos y se ciñe a ellos.
\end{abstract}

Palabras claves: imaginación, Aristóteles, Hobbes, semiología, estética.

The imagination: the beginning, middle and end of Hobbes's state of nature

Abstract: in this article, imagination is the key concept to identify natural man's epistemological evolution. The primacy of the feeling of pleasure is going to expose, in three moments, the development of man's mental faculties. First, natural man's pictorial imagination refers pleasure to objects of sensibility and uses calculating reason to guarantee their stability. Second, an evolution towards a pictorial imagination mediated by a human power capable of bringing men together and imposing itself, in order to refer pleasure to a reality created by common signs and behaviors. Finally, the immediacy of the feeling of pleasure of the pictorial imagination is subordinate to the pleasure derived from the creation of significant linguistic symbols and sticking to them.

Keywords: imagination, Aristotle, Hobbes, semiotics, aesthetics.

Fecha de recepción: 6 de mayo de 2019

Fecha de aceptación: 5 de junio de 2019

Forma de citar (APA): Núñez-Prado, C. (2020). La imaginación: el principio, medio y fin del estado de naturaleza hobbesiano. Revista Filosofía UIS, 19(1), DOI: 10.18273/revfil. v19n1-2020001

Forma de citar (Harvard): Núñez-Prado, C. (2020). La imaginación: el principio, medio y fin del estado de naturaleza hobbesiano. Revista Filosofía UIS, 19(1), 59-79

Christian David Núñez Prado: colombiano. Magíster en Filosofía. Universidad Autónoma de Nariño y Universidad del Valle, Colombia.

ORCID iD: orcid.org/0000-0002-5896-7631

Correo electrónico: christian.nunez@correounivalle.edu.co

*Artículo de reflexión derivado de investigación. 


\section{La imaginación: el principio, medio y fin del estado de naturaleza hobbesiano}

En este artículo se va a orientar la argumentación con la imaginación como concepto clave en la evolución epistemológica del hombre natural. La teoría antropológica de Hobbes incluye de manera determinante la estructura de la imaginación aristotélica. En el estado de naturaleza, la teoría antropológica del homini lupus homini es fundamentada por una teoría de la imaginación que se nutre, para después sobrepasarla, de la teoría aristotélica de la imaginación presente en De Anima.

Se propone una lectura en clave hedonista de la evolución del hombre al interior del estado de naturaleza: la primacía del placer y la continuidad de la imaginación en el desarrollo racional del hombre. Hobbes radicaliza la función pictórica de la imaginación aristotélica y justifica la forma negativa y pasional, primero en acto y después en potencia, de la acción humana. Además, hace derivar la razón de la facultad imaginativa como la específicamente humana. Hobbes después de ocuparse de describir al hombre en los primeros capítulos del Leviatán (1651), continúa describiendo ahistórica y analíticamente, la condición y las aptitudes del hombre natural en su hipotético camino hacia la civilización.

En esta lectura, la hipotética evolución epistemológica del hombre tiene tres fases: primera, la comunidad con las bestias merced de facultades mentales simples dominadas por una imaginación pictórica; segunda, su evolución hacia la sociedad, creada gracias al esfuerzo de un animal humano poderoso que sujeta por fuerza física y mental a varios individuos y permite el desarrollo de una racionalidad incipiente que abre caminos prácticos propios de la humanidad como especie animal y complejiza las facultades mentales; por última, la capacidad únicamente humana del discurso presupone un hombre mentalmente desarrollado para usar y producir signos lingüísticos como naturales para organizar el mundo, natural y humano, según reglas generales.

\section{Aristóteles}

Aristóteles considera la imaginación como una tercera potencia distinta de la percepción, sin embargo, producida por la percepción, y del pensamiento discursivo, si bien abarcada por él. Con su idea de imaginación, Aristóteles critica 
una correspondencia exacta entre la expansión del conocimiento y el aumento de la sensación y parece insinuar la heterogeneidad de realidades de ambas potencias. El inteligir parece ser la realidad de la razón y la palabra objetiva, no algo corporal como la sensibilidad, sin embargo, la imaginación carece de ubicación en la realidad. Según Aristóteles, si sensibilidad y razón fueran coextensivos no existiría el error. El error parece surgir de la diversidad de realidades a las cuales cada una se aplica, pero especialmente gracias a la falta de realidad de la imaginación. De hecho, el error parece ser lo más común en los animales humanos y no la verdad.

La posibilidad del error es lo propio de la imaginación. "La fantasía radica en nuestro poder de conjurar imágenes, aun cuando no se hallen inmediatamente presentes los objetos o fuentes de las sensaciones" (Aristóteles citado en Ferrater Mora, 1990, p. 1216). No obstante, este poder interno provocado por la sensación se puede distinguir en sus distintas manifestaciones de la sensación de objetos externos y del pensamiento (Aristóteles, De anima, III), aunque "de no haber sensación no hay imaginación y sin ésta no es posible la actividad de enjuiciar" (De anima, III, 427b15).

La imaginación parece ser el tránsito, siendo pura imagen neutral, entre sensación e intelecto; crea imágenes con lo dado en la sensación y es ordenada por el intelecto. Por un lado, entonces, la imaginación expresa en imagen lo proveniente de la realidad exterior a través de los sentidos sin dotarla de significado. Por otro lado, es excluida de participar en la facultad intelectiva objetiva, pues esta es acompañada siempre de la verdad y "es que la imaginación puede ser también falsa" (De Anima, III, 428a20).

Aristóteles da un trato mayoritariamente pictográfico al movimiento de la imaginación, se sitúa después de la sensación y antes de la palabra. Por eso, Aristóteles nos dice que la imaginación depende de nosotros, porque no se concierne con la palabra. Para esta última, es necesaria una especie de significados compartidos que nos "fuerza" a una cierta postura y sensación del ánimo, "tratándose de la imaginación, por el contrario, nos quedamos tan tranquilos como quien contempla en una pintura escenas espantosas o excitantes" (De anima, III, 427b20). Aún más,

La imaginación viene a ser la opinión de que [algo] es blanco unida a la sensación de lo blanco y no, desde luego la opinión de que es bueno unida a la sensación de lo blanco. Imaginar viene a ser, pues opinar acerca del objeto sensible percibido no accidentalmente (Aristóteles, De anima, III, 427b25).

Su pobre relación con el lenguaje y su orientación desde la percepción hace que la imaginación no sea usada por la razón y su relación con la moralidad sea distante. Sin embargo, de la argumentación de Aristóteles se desprende la imposibilidad de aislar completamente la imaginación, pues posee un componente 
volitivo dado por la sensación, ya que algo se desea porque es posible mantenerlo en la imaginación mientras está ausente a la sensibilidad, guiando la acción y "la mente presenta estas imágenes como susceptibles de volver a tomar lugar" (Ferrater Mora, 1990, p. 1216). En este sentido, la fantasía tiene una raíz sensitiva, pues produce, almacena y presenta imágenes usadas en una variedad de actividades cognoscitivas que motivan y guían la acción (Shields, 2014), empero, no en un sentido moral.

En esta línea de pensamiento, la imaginación proviene de la sensación y sus imágenes al recaer sobre los mismos objetos de la sensación se hacen similares a los objetos mismos "La fantasía es menos sustitutiva que anticipadora" (Ferrater Mora, 1990, p. 1216). Este movimiento local o interno "no podrá darse sin sensación ni tener lugar en seres carentes de sensibilidad, el ser que lo posea podrá realizar y padecer múltiples acciones gracias a él y, en fin, él mismo podrá ser tanto verdadero como falso" (De anima, III, 428b15).

Aristóteles, entonces, atribuye a la imaginación la sensación imprecisa, la intelección sin rectitud, la posibilidad de la falsa opinión y el error. Por eso su exclusión de las demás facultades es insostenible, tiene que haber cierta relación, así permanezca como imagen pura. A mi juicio, Aristóteles no determina cuándo la imaginación es falsa o verdadera, pues es, también, el instrumento del pensamiento para funcionar en un mundo sensorial. Ella es la facultad interna que coloca imágenes a lo demás. En todo caso, Aristóteles le atribuye una falta de realidad objetiva a la imaginación, realidad que sí tienen las sensaciones, las cuales son siempre verdaderas mientras que "las imágenes son en su mayoría falsas" (De anima, III, 427b10).

En conclusión, cuando la imaginación está unida a la sensación trae falsedad a la realidad sensitiva, igual a la opinión cuando une imágenes y palabras, además de nublar el intelecto impidiendo su capacidad directiva. La imaginación tiene cierta libertad, circunscrita por Aristóteles a la enfermedad y al sueño, para presentar sus imágenes. Mas como no está determinada por ninguna realidad puede recaer sobre cualquier objeto sin necesidad de un estímulo externo, aunque en la vigilia es generalmente circunscrita a la voluntad que extrae de la memoria las imágenes que deseamos en cualquier momento, sin embargo, no en todos los casos está presente y disponible. Parece que los hombres no pueden escapar a esa realidad interior imaginativa con la cual predican el conocimiento del mundo, pues viven sobre todo en el error.

\section{Hobbes}

Hobbes utiliza la concepción aristotélica de la imaginación pictórica para dar cuenta de su antropología. En el estado de naturaleza, el hombre se guía 
especialmente por la capacidad imaginativa pictórica y amoral aristotélica, pero en Hobbes esta sí sirve de insumo para el pensamiento discursivo y la creación lingüística a medida que los hombres entran en relación, hasta desarrollarse de forma compleja y productiva. Voy a exponer la teoría hobbesiana de la imaginación presente en el Leviatán, para después explicar la evolución en tres fases de su antropología de forma comprensiva.

Para Hobbes, la imaginación es un movimiento interno producido por el incesante cambio de la sensibilidad en el tiempo. La sensibilidad en acto se debilita al momento, pero la imaginación es capaz de "retener la cosa vista, aunque menos precisa que cuando la veíamos" (Hobbes, 2005, p. 9). Para Hobbes, el hombre está divisando siempre, en la vigilia, con los ojos cerrados, en ensueño y en el sueño, imágenes interiores y exteriores causadas, en un primer momento, por los sentidos.

Los hombres viven inmersos en imágenes con las cuales miden a los demás hombres, a las otras cosas y a sí mismos (Hobbes, 2005), por eso, para Hobbes la imaginación y los sentidos están conectados en las funciones de la mente: la memoria y el entendimiento. La imaginación, por medio de la memoria, trae a la mente un conjunto de imágenes cargadas de sensaciones placenteras o dolorosas, vividas en diversos tiempos y permite la volición, como en Aristóteles. Cuando la imaginación deja "ver de nuevo" un objeto presentado a los sentidos Hobbes la llama 'imaginación simple', pero cuando las "visiones" combinan diversas imágenes en la mente, la llama 'imaginación compuesta' o ficciones mentales.

En el estado de naturaleza, el hombre se orienta en el mundo gracias a la imaginación que guarda en la memoria experiencias placenteras/dolorosas. Para Hobbes, placer/dolor es una sensación de un objeto acompañada de la consciencia de nosotros mismos, con la cual se ordena no lingüísticamente el mundo de forma dual y, a su vez, de donde nacen otras pasiones.

Cada imagen posee significados no lingüísticos que contienen componentes pasionales, tales como: deseo, esperanza, miedo, entre otros, y asumen forma y significado de acuerdo con las pautas construidas en la imaginación (Engell, 1981). La imaginación compone y transforma las imágenes sensoriales en unidades lo suficientemente comprensivas para ser significativas para cada ser, y permite apropiarse de un sentido de realidad coherente y continuo llamado 'experiencia'.

La 'función compuesta' conecta, fusiona y reordena experiencias e imágenes, siendo esencial para el análisis racional del pensamiento, siguiendo causas y efectos (Engell, 1981). Permite el discurso mental no lingüístico, es decir, pictórico, base del lingüístico, en el cual la mente pasa de un objeto a otro conectándolo con partes de la experiencia. Sin embargo, "[...] un pensamiento cualquiera no sucede a cualquier otro de modo indiferente" (Hobbes, 2005, p. 16). 
Los pensamientos se dan en series y se suceden unos a otros, encadenados a la sensación como causa común, y la transición entre imágenes se da por la regularidad de la transición en la sensación. Si bien, ni sensación ni cadenas de imágenes son enteramente lineales: una sensación antecedente no es seguida de la consiguiente en todos los casos, sino que "tras una sola y misma cosa percibida, viene una cosa y otras otra, así ocurre también en el tiempo, que al imaginar una cosa no podremos tener certidumbre de lo que habremos de imaginar a continuación" (Hobbes, 2005, p. 16).

Aunque las sensaciones sean la causa de las imaginaciones esto no significa que sea equivalentes, pues la imaginación conecta diferentes partes de la experiencia con lo presente y las cadenas imaginativas pueden conectarse de forma polivalente. No obstante, una viene antes de la otra como su causa, así el efecto sea o no el mismo en todos los casos. En especial, porque las sensaciones no son experimentadas neutralmente, las placenteras/dolorosas tienen mayor intensidad en la imaginación, en tanto nos damos cuenta de ellas y de nosotros mismos $^{1}$ : "tan fuerte es, a veces, que impide y rompe nuestro sueño" (Hobbes, 2005, p. 17).

De esta intensidad surge el deseo/aversión por una cosa particular y también el pensamiento que calcula las acciones necesarias para procurarse/evitar lo ya experimentado, en este orden de cosas se encuentra lo necesario para la supervivencia y el funcionamiento biológico. Esta forma de orientación en el mundo es compartida por hombres y animales.

La diferencia hombre-animal nace de la invención imaginativa de procederes: a partir de algo ausente, el hombre se traslada a sus recuerdos y se ubica en experiencias pasadas. Además, imaginativamente, el hombre puede prever a partir de imágenes hipotéticas y adelantarse a los sucesos, hasta llegar a las últimas consecuencias de alguna ficción mental, "lo que los latinos llamaban sagacitas" (Hobbes, 2005, p. 18). Aunque, en este caso, toda conjetura tiene un grado de falacia, dada la apertura a todas las posibilidades del futuro.

El futuro, entonces, puede ser configurado imaginativamente gracias a la previsión y, según Hobbes, acierta, suficientemente, el más prudente, quien posee más signos de la experiencia en aquello a lo que se dedica. Un signo es la unión mental de las causas y los efectos de una cosa, y versa sobre la comprensión de la experiencia y sus efectos inmediatos y posibles. El prudente tiene más signos para observar en su mente y puede prever más acertadamente el futuro o analizar el pasado y, de forma empírica, obtener parámetros para la acción presente o futura.

1 "Hobbes, define el placer y el dolor como sensaciones, pero no causadas por el movimiento de objetos externos, sino por el movimiento de nuestro propio cuerpo. Podríamos decir que más que percepción, el placer y el dolor serían apercepciones de nuestro propio ser" (Jiménez, 2012, pp. 275-276). 
La función compuesta de la imaginación complejiza paulatinamente los signos cuando los hombres entran en sociedad y se vuelve ilimitada cuando efectúan el pacto, donde Hobbes da un tratamiento discursivo a la imaginación, subordinando su capacidad pictórica. Aquí, el entendimiento parece estar compuesto de imágenes dotadas de palabras, las cuales permiten a la mente constituir signos voluntarios del lenguaje usados para transmitir a otros hombres contenidos mentales imaginarios (Engell, 1981), es decir, en forma de concepciones y pensamientos (Duncan, 2013). En suma, la imaginación para Hobbes no es mecánica sino un poder vivo y activo contenido en la mente que permite el desarrollo del lenguaje.

\section{El camino de la imaginación en el hombre natural}

Interpretaré las tres causas principales de discordia halladas en la naturaleza del hombre presentes en el capítulo XIII del Leviatán como tres momentos de desarrollo de las facultades mentales, allí se observa lo siguiente: primero, se puede ver el predominio de una imaginación pictórica individual que refiere el placer a los objetos de la sensibilidad y utiliza la razón calculadora para asegurárselos de forma continua; segundo, el paso hacia una imaginación pictórica mediada por un poder capaz de reunir a los hombres e imponerse, que refiere el placer hacia una realidad de signos y comportamientos comunes; por último, el placer de la imaginación pictórica es subordinado por el placer derivado de la creación de símbolos significativos lingüísticos y se ciñe a ellos.

Para Hobbes, las tres causas principales de discordia halladas en la naturaleza del hombre son: "[...] primera, la competencia; segunda, la desconfianza; tercera, la gloria" (2005, p. 102). La naturaleza es el lugar de la igualdad general entre los hombres, todos obtienen los mismos beneficios naturales: la fuerza corporal y la sagacidad en el entendimiento. En particular, los hombres difieren en grados, pero esta diferencia "no es tan importante que uno pueda reclamar, a base de ella, para sí mismo, un beneficio cualquiera al que otro no pueda aspirar como él" (Hobbes, 2005, p. 100).

En el estado de naturaleza, Hobbes analiza las facultades mentales antes de la aparición del lenguaje y encuentra en ellas "una igualdad más grande, entre los hombres, que en lo referente a la fuerza" (Hobbes, 2005, p. 100). Una suerte de estructura subjetiva general de pensamiento, sentido e imaginación con la cual se enfrentan a un mundo cambiante y diverso, pero que los lleva a dedicarse a las mismas cosas.

"De esta igualdad en cuanto a la capacidad se deriva la igualdad de esperanza respecto a la consecución de nuestros fines" (Hobbes, 2005, p. 101). Los hombres experimentan un mundo gracias a la igualdad general de sus capacidades físicas y mentales, sufren alegrías/dolores por las mismas cosas, experimentan de la misma 
forma peligros y penalidades respecto de otros animales (humanos) o fenómenos naturales.

En lo particular, la igualdad de la experiencia se ve perturbada por "la diversidad de nuestra percepción de ella, motivada por las diferentes constituciones del cuerpo, y los prejuicios de opinión prestan a cada cosa el matiz de nuestras diferentes pasiones" (Branda, 2008, p. 75). Diversidad en la percepción debida a cierta libertad de la imaginación que crea una imagen que funciona como una consciencia, de la cual todas las imaginaciones forman parte, una imagen compuesta de sí mismo que acompaña a todas las experiencias placenteras/ dolorosas conservadas en la memoria, una imagen interior con la cual se mide todo lo demás.

En términos generales, todos los hombres son iguales en la estructura de su imaginación y en sus productos, pero, en particular, cada cual posee una imagen de sí con la cual señaliza su mundo y le otorga un significado en términos hedonistas, produciendo imágenes individuales de cada cosa. Hobbes alerta sobre el destructivo poder creativo de la imaginación, en tanto determina individualmente la relación con el mundo y rompe la regularidad general de la estructura de las facultades mentales. La imaginación permite al hombre crear imágenes sobre sí mismo, conectadas a una causalidad empírica pero combinadas de tal manera que se alejan de ella.

Con esta imagen-conciencia los hombres juzgan arbitrariamente, además del mundo, la interioridad de los demás hombres. Ella es "un concepto vano de la propia sabiduría", con el cual cada hombre valora su experiencia y su poder excesivamente y desvaloriza casi toda otra, excepto "a quienes reconocen su valía, ya sea por la fama de que gozan o por la coincidencia con ellos mismos" (Hobbes, 2005, p. 100).

En este sentido, los hombres naturales contemplan su propio poder cuando actúan, su voluntad nace del deseo de apropiación/aborrecimiento de la experiencia de objetos placenteros/dolorosos. En otras palabras, la voluntad nace de lo que "primero ha sido imaginado en nuestra mente [...] y depende siempre de un pensamiento precedente de adónde, cómo y qué" (Hobbes citado en Jiménez, 2012, p. 276). En este sentido, las pasiones necesitan la ayuda de la imaginación y, más importante aún, el miedo, el deseo y la esperanza no son mociones voluntarias sino la voluntad misma (Branda, 2008).

La experiencia inmediata de lo placentero/doloroso da paso a la voluntad, al deseo/aversión y subsecuentemente a lo bueno/malo para mí. Aquí Hobbes conecta la imaginación pictórica aristotélica con una moral individualista: "El objeto deseado será considerado como placentero, ergo bueno [para mí] [...]. Es 
el propio hombre el que establece qué es lo bueno y qué es lo malo" (Branda, 2008, p. 70). Esta es la razón por la cual en el estado de naturaleza no existe una moral universal y objetiva para establecer jerarquías de poder.

La violencia nace del complemento de ambos aspectos de la imaginación, general y particular. Por un lado, la imaginación exalta, en general, las mismas imágenes de objetos deseables a todos y con ello despierta una volición coincidida sobre los mismos ${ }^{2}$. Por otro lado, las diferentes imágenes del propio poder chocan entre sí porque cada hombre se erige a sí mismo como único parámetro de lo bueno y lo malo.

Si los hombres desean los mismos objetos placenteros y, además, creen tener la capacidad de acceder a ellos, surge lógicamente el enfrentamiento violento. Sin un desarrollo importante de otras capacidades cognoscitivas, el hombre se ve arrastrado por una voluntad de poder autotélica sin ningún parámetro para reprimir su volición, su mente es dominada por las visiones más impresionantes de la imaginación y considera a quien tenga el poder de estorbarle en la posesión como un obstáculo a remover.

En suma, la consecuencia del imperio general y particular de la imaginación es la guerra de todos contra todos, "la identidad última del estado de naturaleza" (Piccinini, 2005, p. 104). Un estado invariable de agresiones presentes y posibles donde un primer agresor puede prever que vengan otros con sus fuerzas unidas para desposeerle y privarle, y el nuevo invasor, a su vez, se encuentra en el mismo peligro respecto a otros (Hobbes, 2005).

Por esto Hobbes nos dice: "los hombres no experimentan placer ninguno (sino, por el contrario, un gran desagrado) reuniéndose" (Hobbes, 2005, p. 102). La preponderancia de la imaginación pictórica hace asociales a los hombres naturales, quienes se encuentran en constante competencia para alcanzar la posesión de los objetos de sus deseos, buscan lo bueno para cada uno. Así, se crea un estado persistente de guerra real posible ${ }^{3}$, donde el impulso a la violencia

\footnotetext{
2 Branda nos habla de la variabilidad de los objetos de las pasiones humanas, sin embargo, su argumento choca con el mío, en tanto la igualdad de la experiencia y de las capacidades no lleva a los hombres a desear objetos variables sino diversos objetos. El movimiento de la sensibilidad no se refiere a una experiencia novedosa de placer/dolor de los objetos cada vez, sino a una experiencia conjunta y perpetua de los diferentes objetos. Empero, con esto no quiero decir que cada hombre desee exactamente lo mismo que otro, pues el gusto es particular, sin embargo, sí hay un cúmulo de objetos que todos desean generalmente. La variabilidad de los objetos de las pasiones humanas podría minar la idea de un estado de violencia de todos contra todos engendrado por la apropiación de lo que a cada uno le parece bueno y podría, en último término, impedir la reunión de los hombres en los mismos lugares donde se encuentran los objetos generales de deseo.

${ }^{3}$ En palabras de Hobbes, este tipo de guerra "no consiste solamente en batallar, en el acto de luchar, sino que se da durante el lapso de tiempo en que la voluntad de luchar se manifiesta de modo suficiente. Por ello la noción del tiempo debe ser tenida en cuenta respecto a la naturaleza de la guerra, [...] en la disposición manifiesta a ella durante todo el tiempo en que no hay seguridad de lo contrario" (Hobbes, 2005, p. 102).
} 
depende del beneficio inmediato. En esta situación de desconfianza generalizada, la imagen del propio poder genera una racionalidad anticipadora. Se trata de una racionalidad antecedente-consiguiente que tiene como objeto calcular la obtención, duración e intensidad del placer de los objetos lo más inmediatamente posible.

La concatenación de las diferentes imágenes de violencia entre hombres da paso a la configuración estable de una experiencia dolorosa en cada encuentro y desarrolla la anticipación mental para crear rutas de acción, mezclando experiencias y ficciones de la mente como parámetro de lo que probablemente sucederá. Por eso, la anticipación juega un rol crucial para el desarrollo mental del hombre. Se trata de una racionalidad primaria enteramente referida a mantener en el tiempo el placer de y en sus vidas, un fuerte deseo de autoconservación como fin de todas sus acciones $y$, complementariamente, el temor a la muerte.

Gracias a esta racionalidad calculadora, el individuo intenta cerrar la brecha, ilusoria y conjeturalmente, entre continuidades y discontinuidades de los fenómenos y de las acciones presentes y posibles. La imaginación pictórica tiene la racionalidad calculadora básica como instrumento para funcionar en un mundo natural.

En conclusión, "la guerra encuentra sus caminos abiertos en la escasez de lo que todos quieren, [...] en las ilusiones de cada uno" (Piccinini, 2005, p. 101). La experiencia estable de lucha posible, provocada por la imaginación pictórica, para Hobbes, impide el desarrollo de las características propias de la humanidad como la conocemos: el cultivo, la navegación, las construcciones, los calendarios, las artes, el lenguaje y la sociedad. Además, el hombre teme continuamente la muerte violenta y su vida "es solitaria, pobre, tosca, embrutecida y breve" (Hobbes, 2005, p. 103).

Con todo lo anterior, los hombres estructuralmente iguales se asemejan a los animales de una misma especie, tienden a alimentarse de las mismas cosas y consideran placenteros los mismos lugares: ríos, cuevas, árboles frutales, ganados y demás. Por eso, se encuentran en los lugares donde se produce el placer. Además, como todos se estiman excesivamente a sí mismos y tienden a desear lo mismo cuando se encuentran, el desprecio se hace evidente entre las diferentes imágenes del propio poder, pues "cada hombre considera que su compañero debe valorarlo del mismo modo que él se valora a sí mismo" (Hobbes, 2005, p. 102), y la violencia es la forma de objetivar el reconocimiento del verdadero valor de cada uno. Es más, "[...] naturalmente se sale de la presunción de autosuficiencia sólo por la tangente de la guerra" (Piccinini, 2005, p. 101).

La igualdad de las facultades hace coincidir a los hombres, pero la identidad de deseos los hace reunirse, paradójicamente, a través de la violencia. La violencia es 
el criterio objetivo del establecimiento de jerarquías entre los hombres. Pero iqué hace que los hombres se mantengan reunidos? La gran desconfianza y displacer entre los hombres hace parecer imposible una reunión duradera, sin embargo, la anticipación de las imágenes dolorosas no solo impulsa a los hombres a la violencia por la violencia ${ }^{4}$, sino también a buscar la seguridad para defender su vida y sus posesiones.

Los hombres condicionados empíricamente por la fuerza de la imaginación pictórica no se encuentran gracias a una decisión racional ni por conveniencia sino por la fuerza ejemplar de ciertas imágenes impresionantes. Ciertos sitios a los que llamaré "fuentes de placer", donde los objetos deseables se encuentran en abundancia y el placer de objeto es continuo, por ejemplo: cualquier manzana provee un placer inmediato, pero el manzanero provee objetos de placer continuamente; por eso aquí los hombres se encuentran.

Los hombres concurren en las "fuentes de placer" por la utilidad de tener a mano lo necesario para la vida y reducir el esfuerzo biológico de autoconservación. Acto seguido, ocurre la lucha de todos contra todos, donde algunos hombres sobresalen. Según Hobbes, no todos están dispuestos a arriesgar su integridad ante la evidencia de una fuerza superior, algunos se desalientan a luchar ante la certeza de su falta de poder, y el enfrentamiento a muerte se da solo entre hombres con convicción en la imagen de su propio poder y la capacidad de objetivarla; de estos hombres emerge un ganador o grupo de ganadores ${ }^{5}$ reconocido y admirado a la vista de todos.

El reconocimiento de la fuerza engendra temor o amor en los demás y establece las relaciones entre animales humanos. Los hombres no alcanzan la seguridad en soledad sino por un 'hombre fuerte' que ejercita su fuerza ante los demás de forma constante para "arrancar una mayor estimación de sus contendientes, infligiéndoles algún daño, y a los demás por el ejemplo" (Hobbes, 2005, p. 102). De esta forma, la "fuente de placer" es conquistada por un poder capaz de atemorizarlos a todos, no solo directamente sino, especialmente, por el ejemplo.

El reconocimiento de la fuerza o la reputación de poder impide la libertad positiva de los hombres y transforma las relaciones negativas, competitivas, discordantes y violentas de los hombres naturales, en concordantes y positivas. Con ella, Hobbes muestra el poder social fundante de alguien con la fuerza (mental o física) suficiente para dominar a una multitud de hombres, imponerse a ellos y

\footnotetext{
${ }^{4}$ Esto es, ayudada por la racionalidad, pero sin mediación de parámetros racionales.

${ }^{5}$ En vista de la molestia de nombrar lo mismo en singular y en plural, a continuación, voy a referirme solo a un hombre fuerte $y$, posteriormente, a un soberano; entendiendo que también pueden ser varios, tanto al interior de una sociedad de hombres como en diferentes lugares del planeta. La singularidad es un recurso explicativo ejemplar.
} 
sujetarlos mediante el temor, la conveniencia o alguna otra pasión producida por su magnífica fuerza. Para explicar el poder social fundante del hombre fuerte me apoyo en lo que Zarka (2006) Ilama 'la semiología del poder', pero aplicado al estado social de los hombres en el estado de naturaleza ${ }^{6}$.

Cuando surge este poder, la voluntad de cada hombre se ve refrenada por una voluntad superior y se complejiza la sensación de placer: adquiere formas mediatizadas de deseo sin perder su referencia a la inmediatez'. El 'hombre fuerte' genera una experiencia placentera de segundo orden orientada hacia los signos propios del espacio fundado al interior de los hombres reunidos, parámetros comunes y estables de comportamiento que transforman la desconfianza en confianza de cada uno con cada otro.

¿Cómo sucede este paso? El animal humano obtiene el mismo placer sensorial inmediato de los objetos, pero su posesión y el mundo natural, en general, dejan de existir como condición empírica inmediata, merced de la preponderancia de una realidad semiológica creada, donde comienzan a surgir y a complejizarse signos compartidos propios de los hombres como especie, base del advenimiento del lenguaje.

Solo aquí el poder natural, esto es, "la eminencia de las facultades del cuerpo o de la inteligencia, tales como una fuerza, belleza, prudencia, aptitud, elocuencia, liberalidad o nobleza extraordinaria" (Hobbes, 2005, p. 69), da paso al poder entendido instrumentalmente, es decir, al poder entendido como medio para adquirir más poder, "como la riqueza, la reputación, los amigos, y los secretos designios de Dios, lo que los hombres llaman buena suerte" (Hobbes, 2005, p. 69).

Aparecen paulatinamente signos y señales comunes, acciones entendidas por todos que organizan la sociedad en lineamientos básicos de mando y obediencia, de forma similar como los orangutanes, los lobos y los leones alfa muestran, mediante el lenguaje corporal y sonoro, los comportamientos permitidos al interior de la manada: sumisión, respeto, jerarquías, diferentes roles, entre otros.

\footnotetext{
${ }_{6}^{6}$ Para mí, la lectura de Zarka defiende bien la aparición de signos de poder en el estado de naturaleza, sin embargo, coloca el paso del primer umbral que lleva de lo cuantitativo, del efecto físico, a lo cualitativo, a la obtención de un bien imaginado, demasiado "lejos", en la representación: lugar "donde toda reacción fisiológica se transforma en apariencia subjetiva" (Zarka, 2006). Según mi lectura, la representación es tal umbral donde todo es apariencia subjetiva, tanto por su lugar dentro del orden de la argumentación del Leviatán como por su carácter artificial, no obstante, se puede ver la aparición de algunos signos básicos de poder cuando el desarrollo cognoscitivo del hombre pasa de una imaginación pictórica a una imaginación "social".

Como he dicho anteriormente, postulo una relación de continuidad entre el hombre natural y el hombre civilizado, pero me parece enriquecedora y acertada la afirmación de Rosello, en tanto lleva a las mismas conclusiones de reivindicar la continuidad, en la teoría política de Hobbes, del animal en el hombre; para él, lo humano nunca deja de ser, al menos en potencia, el imperio de la voracidad. "Puesto que los humanos son ellos mismos también animales, nunca dejan de llevar consigo la dimensión de lo no político" (2014, p. 21).
} 
En sociedad y por imposición, se establece el significado de las acciones comunes, en un principio se señalizan o marcan convencionalmente ciertos sitios, objetos, animales o comportamientos, lo cual da inicio, si el 'hombre fuerte' mantiene a los hombres reunidos suficiente tiempo, a una semiología del poder y de la obediencia.

Las señales permiten distinguir y traer de nuevo a la memoria algún lugar u objeto y otorgarle un significado que él propiamente no posee, por ejemplo: una $X$ en un árbol, que significa el fin del territorio o una piedra magna que señaliza el paso más seguro a través de un río. Para Hobbes, el hombre inventa las marcas por la necesidad de comunicación con los contenidos mentales de otros hombres, incluso de los no presentes; así, cuando se ejercita esta invención de forma social se da paso a la creación de nombres.

La marca deja de estar ligada a un objeto y expone un pensamiento. Al principio, el lenguaje es solo una forma particular de la marca. "Así, el primer uso de los nombres es servir como marcas o notas del recuerdo" (Hobbes, 2005, p. 23), pero se habla del uso de signos "cuando varias personas utilizan las mismas palabras para significar (por su conexión y orden), una a otra, lo que conciben o piensan de cada materia; y también lo que desean, temen o promueve en ellos otra pasión" (Hobbes, 2005, p. 23).

Los signos son ficciones mentales que agrupan causas y consecuencias particulares en una generalidad significativa, esto es una herramienta de la mente para hacer más sencilla la relación con el mundo, pero también permite la horizontalidad de ficciones mentales que "integra los poderes de varios hombres unidos por el consentimiento de una persona natural" (Hobbes, 2005, p. 69).

El lenguaje tiene como condición a la sociedad ${ }^{8}$, pues solo en ella aparece la necesidad semiológica de horizontalizar las pasiones individuales de los hombres y ordenar el mundo compartido. En este sentido, toda agrupación de hombres solo es posible a través del disciplinamiento semiológico de la parte animal. Por eso, el placer se debe desplazar de la inmediatez de la obtención de las ficciones individuales, de lo bueno para mí, a lo mediato de los signos, la proyección del deseo que toma en cuenta los deseos de los demás para articular sus voluntades en torno al mandato del 'hombre fuerte', el cual brinda un bien aparente futuro a los hombres reunidos: conservar la vida de la forma menos gravosa posible.

\footnotetext{
${ }^{8}$ Parece que esta lectura va en contravía de la de Zarka cuando afirma: "porque Hobbes hace de la palabra y de la comunicación verbal la condición de la sociedad, y no al revés, su filosofía política es una semiología del poder y no una sociología del poder" (2006, p. 109). Sin embargo, creo que el lenguaje social es solo posible porque el hombre ya tiene una imagen de sí, un lenguaje interior en imágenes donde el lenguaje social puede encontrar asidero y se puede desarrollar. Además, no sé hasta qué punto sea determinante en la teoría hobbesiana la preponderancia de uno o de otro, al fin y al cabo, Hobbes desarrolla una teoría de signos para fundamentar su teoría política.
} 
La sociedad de los animales humanos surge del dominio por el poder físico, pero se establece por el reconocimiento de los signos de poder. El 'hombre fuerte' hace posible un 'sentido de lo bueno', es decir, la proyección de un placer estable al interior de los hombres reunidos que limita las pasiones y deseos inmediatos en pos de la consecución de un bien futuro igual para todos.

Empero, en este momento, ni el "fuerte", ni los signos son tan poderosos y objetivos como para impedir la violencia, ni el ejercicio de las distintas voluntades particulares; el estado de guerra de todos contra todos no se desvanece por la aparición de los signos. Todo depende de la astucia y fuerza del 'hombre fuerte' para trasladar el instinto de autoconservación particular a la generalidad de la sociedad, brindando protección a cada uno frente al otro, a través de los signos defendidos/castigados, que son la única forma que crea relaciones de confianza hacia el interior. De la misma manera como lo haría un macho alfa, que puede ser reemplazado dada su ineficacia para controlar otros machos poderosos.

Como he dicho anteriormente, el poder del hombre fuerte no es solo físico sino significativo y lo inserta en el campo de las creencias, en este sentido Hobbes dice que: "la naturaleza del poder es, [...] creciente a medida que avanza" (Hobbes, 2005, p. 69). Con el signo, el poder adquiere cierta autonomía respecto de lo físico, en tanto es una presencia condicionante de todas las acciones sin necesidad de su presencia fáctica.

Hobbes iguala poder y apariencia de poder en el concepto de reputación, "porque con ella se consigue la adhesión y afecto de quienes necesitan ser protegidos [...] y constituye un medio para tener la asistencia y servicio de varios" (Hobbes, 2005, pp. 69-70). El 'sentido de lo bueno' permite el salto cualitativo del uso del poder al poder entendido como intercambio, en relación con otros, como signos de poder.

Por consiguiente, sólo es poder el exceso significante, es decir, lo que en el poder o por algún otro medio es signo de poder [...]. Todas las pasiones y los comportamientos humanos se convierten en intercambios de signos, [...] y el poder de un hombre no se mide por sus efectos directos, sino en relación con el poder de otros. [...] El poder, en el intercambio, sólo existe en cuanto que es capaz de ofrecerse como espectáculo por medio de unos signos a la mirada de los demás, quienes expresan la evaluación que hacen de ellos por medio de otros signos: los signos de honor [...]. Estos signos son actos, gestos, comportamientos y palabras (Zarka, 2006, pp. 100-101).

De acuerdo a la anterior cita, el poder del "fuerte", en tanto dominio prolongado, implica la producción de signos que acrediten su poder para que los demás actualicen lo que su poder significa, es decir, es valioso por su éxito o prudencia, pero es honrado porque puede proteger, ayudar o perjudicar a los 
demás, o parece que lo hace, con lo cual adquiere una reputación de sabiduría o de buena fortuna y genera un gusto por su mando que dispone a la multitud de hombres hacia la obediencia, a creer, confiar y apoyarse en él (Hobbes, 2005). Esta disposición hacia la obediencia se generaliza socialmente cuando todos honran los juicios del 'hombre fuerte', coincidan o no con su opinión, pero sí en la idea de su virtud y de su poder para gobernarlos.

Sin embargo, el valor de su poder "no es absoluto, sino una consecuencia de la necesidad y del juicio de otro" (Hobbes, 2005, p. 71). El valor del 'hombre fuerte' y de cada hombre, dentro de la red de intercambio semiológico no es absoluto, sino que es lo que significa el uso de su poder en cada caso particular respecto de todos los demás, esto en términos del beneficio social. Por eso me gustaría decir: ningún hombre que guíe sus acciones mayormente por la imaginación pictórica asumirá este cargo por largo tiempo, ni podría llevar a los hombres hacia la civilización, pues no puede mandar basado en juicios ni caprichos privados, al contrario, debe ser consciente de la faceta semiológica del poder y leer en sí mismo, en cada decisión, a la humanidad entera (Hobbes, 2005).

En conclusión, el valor atribuido al 'hombre fuerte' estriba en los efectos producidos por el poder que consisten en obtener para los demás, diría yo, en comunicación con los demás, pero a la vez con autonomía, algún bien aparente futuro. Con la erección y ejercicio de un 'sentido de lo bueno' el poder produce otros efectos que, posiblemente insospechados para el 'hombre fuerte', promueven un tipo de fines inimaginables para los hombres naturales en general: el bien común. La posición de poder y de obediencia, entonces, abre un tipo diferente de experiencia humana y de relación con el mundo.

He venido argumentando que la discordia se encuentra en la naturaleza imaginativa del hombre, que gradualmente se subordina a la racionalidad como consecuencia del desplazamiento del sentimiento de placer inmediato hacia uno mediatizado por signos. Todo esto gracias a factores externos que movilizan las capacidades mentales humanas a la necesidad de creación de ficciones mentales, tales como la violencia y la fuerza mental y física de un 'hombre fuerte'.

Hobbes sitúa al 'hombre fuerte' en una posición suprema, a una distancia insalvable del grupo de hombres. 'Hombre fuerte' y multitud a partir de la exclusión entran en comunicación. Sin embargo, la completa separación del 'hombre fuerte' de los demás es condicionada por su identidad ontológica. Así, le toca de forma horizontal todo lo que afecta o motiva en esencia a cualquier hombre, pues tiene idénticos medios racionales y pasionales para procurarse la conservación de su propia vida. De lo anterior se puede deducir que, para Hobbes, la forma general de los pensamientos y pasiones de los hombres permanece inmutable en el tiempo, la diferencia radica en su aplicación a casos particulares, la cual depende de la constitución individual, la experiencia y la educación. 
Esta igualdad supone, en general, la posibilidad de un diálogo racional entre las pasiones y necesidades de quienes están supuestos a obedecer y quien manda, pues "la razón siempre calcula sobre el campo de las pasiones" (Branda, 2008, p. 75). En particular, la experiencia humana se bifurca, para dar paso a más, en experiencia del 'hombre fuerte' y experiencia de la multitud de los hombres reunidos.

A pesar del despliegue de la reputación de poder, no todo es paz al interior de la multitud reunida. La tercera causa de discordia entre los hombres: la gloria, impide una relación de continuidad mando/obediencia entre hombres sociales y el 'hombre fuerte'. Hobbes aúna la gloria a la objetivación del concepto del propio poder creado en la imaginación, pero con el concepto de vanagloria, diferencia las imágenes ilusorias con las cuales cada hombre cree tener un poder mayor que otros.

Por un lado, la vanagloria se trata de un placer de la mente originado por la imagen ilusoria del propio poder cuando este se sabe ausente en completa abstracción de otros hombres. La vanagloria continúa acompañando a los hombres siempre, una ilusión del propio poder por adulación o simple suposición merced de la imaginación pictórica. Por otro lado, "Hobbes often uses glorying as synonymous of triumph of a man over another" (Slomp, 1990, p. 140).

La gloria, entendida como el placer de compararnos a nosotros mismos con otros en acciones posibles, presentes o pasadas, y de notar nuestra superioridad sobre ellos, alienta el deseo de poder de cada hombre y lo dota con la suposición de confianza en sus capacidades para obtener un designio. Sin embargo, la gloria, en esta línea argumentativa, implica un uso productivo de la imaginación pictórica, en tanto no tiene que ver directamente con un objeto, sino con una ficción de la mente condicionada por la red semiológica social, pues

Recurre a la fuerza por motivos insignificantes, como una palabra, una sonrisa, una opinión distinta, como cualquier otro signo de subestimación, ya sea directamente en sus personas o de modo indirecto en su descendencia, en sus amigos, en su nación, en su profesión o en su apellido (Hobbes, 2005, p. 102).

Según la anterior cita, la gloria es una categoría pública. Ella presupone una realidad semiológica común y, además de esforzarse por conseguir signos de estimación y acabar con los de desprecio, ella misma es generadora de nuevos signos que no necesitan, en principio, de un signo común. Con otras palabras, intenta introducir signos de carácter privado en la red semiológica común, esto genera una tensión entre lo establecido y lo que ella intenta establecer. 
Lo anterior puede llevar tanto a la violencia como a la diversificación de los lineamientos de mando y obediencia al interior de los hombres reunidos; dado que ningún hombre pierde sus pasiones y deseos privados. Con el deseo de gloria se da una insubordinación respecto de los contenidos de los signos compartidos. Sin embargo, no siempre se da de tal forma que lleve a una violencia desnuda, pues Hobbes liga la gloria al valor, al honor y al poder. Es decir, se liga la gloria a la consecución de algo más, al espectáculo de la mirada de los demás, a la consecución de signos de poder.

El honor es "la manifestación del valor que mutuamente nos atribuimos" (Hobbes, 2005, p. 71). Hobbes "argues that to honour a man is to value him [...] and as in other things, so in men not the seller, but the buyer determines the price" (Hobbes citado en Slomp, 1990, p. 137).

Domino y victoria, honorable, [...] buena fortuna (si dura) [...] los ricos son honorables porque tienen poder [...] magnanimidad, liberalidad, esperanza, valentía, confianza son honorables porque proceden de la consciencia de poder. [...] La resolución oportuna [...] gravedad. [...] Ser distinguido, es decir, conocido por las riquezas, los cargos, las acciones grandes o la bondad eminente, es honorable, porque constituye un signo de poder de quien es distinguido. [...] Descender de padres distinguidos es honorable. [...] Las acciones que proceden de la equidad y van acompañadas de pérdidas, son honorables porque son signos de magnanimidad y la magnanimidad es un signo de poder. [...] La ambición de grandes riquezas son honorables, como signos de poder para obtenerlas. No altera el caso del honor el hecho de que una acción (por grande y difícil que sea y, aunque, por consiguiente, revele un gran poder) sea justa e injusta: porque el honor consiste solamente en la opinión de poder (Hobbes, 2005, pp. 73-75).

De lo anterior, es evidente que el honor implica una pluralidad de hombres distinguidos en diferentes actividades, con diversas disposiciones de carácter, acciones o instrumentos que implican signos de poder y beneficio para los demás. Esto se podría dar de la siguiente manera: como algunos hombres resaltan en los puestos asignados al interior de la manada, desean para sí más poder del asignado a su posición, buscando conquistar e invadir el orden social con la creación de nuevas rutas de acción que permitan la expresión de nuevos signos de poder que, o bien llevan a la lucha por rivalizar con el 'hombre fuerte' o, siendo consentidos por este, expanden la cantidad de actividades y signos sociales.

En evitar la violencia que destruya el orden radica la virtud del 'hombre fuerte', pues no puede impedir con la fuerza la erupción de las diferentes pasiones ni la creación semiológica propia de cada hombre, sino que su poder estriba en dialogar con ellas y acrecentar su poder, transformando la oposición en creación, de forma racional. 
La creación da paso a la expansión de los signos comunes, complejizándolos para que tomen en cuenta más que todo ficciones de la mente, cosas que no se encuentran en el mundo empírico ni signos sociales emanados del mando, sino signos que abarquen los sentimientos, los pensamientos y las relaciones humanas. Aquí los hombres son capaces de inventar "fuentes de placer" simbólicas que abren la puerta a una sensación de placer en la producción de símbolos, acciones y objetos derivados de estos que diversifican, gracias a la expansión del lenguaje, el número de jerarquías de mando y obediencia.

Con la gloria los hombres empiezan a tomar como natural su capacidad de organizar el mundo, natural y humano, según la creación de diversas reglas generales. La preponderancia de la racionalidad sobre las pasiones aumenta gracias a la producción de signos por parte de los diferentes hombres, gracias al incesante deseo de poder como el resorte de todas las acciones individuales, la competencia por los diferentes medios de honor pasa de lo físico a lo simbólico y permite explicar el comportamiento no siempre violento de los hombres a partir de motivaciones similares.

Esta desviación de la inmediatez de la violencia pictórica se ve reflejada en la exclusión entre la gloria y la muerte, pues ningún hombre puede experimentar la gloria después de muerto. El deseo de gloria está mediatizado racionalmente por el 'sentido de lo bueno' para todos, es decir, por el beneficio, o supuesto beneficio, que los espectadores creen obtener de honrar a alguien.

La violencia se traslada hacia afuera de la sociedad y se refiere a acciones laudables y de conquista para acrecentar el poder al interior. Por eso, y como dije anteriormente, no se trata de que se erradique la violencia al interior, menos en el estado de naturaleza, pues todos los hombres conservan su imaginación pictórica, ni se trata de que los hombres eviten arriesgar su vida.

Al volverse obvia la capacidad creativa de cada hombre, la preponderancia de la razón se amplía, pues implica la capacidad racional de sopesar las ventajas y desventajas del sometimiento de encontrarse al interior de un grupo de hombres. Sin embargo, a pesar de sentir el temor de la sujeción, también mantienen la libertad de desobedecer.

Vale la pena recordar que seguimos en el estado de naturaleza, por eso la capacidad creativa ilimitada de los hombres todavía no puede crear los artificios necesarios para una vida civilizada. Hay una creación diversa de signos gracias a la función productiva de la imaginación, mas no una recreación ilimitada de la subjetividad de forma que pueda crear artificios como el Estado, hospitales, escuelas, entre otros, prerrogativa posibilitada únicamente por la institución política. 
En conclusión, he mostrado la evolución de las capacidades mentales de los hombres, desde una capacidad puramente pictórica de la imaginación hacia el desarrollo de una racionalidad cada vez más compleja que permite la duración de la sociedad a través del desplazamiento del sentimiento de placer del objeto al signo.

La paz se estabiliza paulatinamente a medida que los hombres tienen las herramientas cognitivas para calcular la relación entre sus comportamientos y ese estado de guerra de todos contra todos (Rutheford, 2015), de esta forma la diversidad de apetitos y deseos y, con ello, las acciones necesarias para conseguirlos, pasan de ser particulares a generales y disponen a todos a actuar de una forma predecible racionalmente.

No todos los individuos respetarán estos 'dictados de la razón' en el estado de naturaleza, por eso se hace necesario un Estado, donde las leyes sean determinantes para la acción de las personas bajo castigos y penas que obligan a cumplirlas (Rutheford, 2015). Una vez traspasados los tres estados de las facultades cognitivas, los hombres guían mayoritariamente sus vidas a partir de convenciones sociales.

\section{Referencias}

Aristóteles (1995). Acerca del alma. Madrid: Planeta-Agostini.

Branda, C. (2008). Razón natural y racionalidad política en el Leviatán de Thomas Hobbes. Res publica: Revista de filosofía política, 20, 67-94.

Engell, J. (1981). The creative imagination: Enlightenment to romanticism. Cambrigde: Harvard University Press.

Duncan, S. (2013). Thomas Hobbes. En E. Zalta (ed.), The Stanford Encyclopedia of Philosophy. Stanford: Metaphysics Research Lab, Stanford University. Recuperado de http://plato.stanford.edu/archives/sum2013/entries/hobbes/

Hobbes, T. (2005). Leviatán. Ciudad de México: Fondo de Cultura Económica.

Jiménez, D. (2012). La prioridad del placer sobre el deseo en la teoría de las pasiones de Thomas Hobbes: una explicación, materialista, mecanicista y fisiológica. Cauriensia, VII, 271-280.

Ferrater Mora, J. (1990). Diccionario de filosofía. Buenos Aires: Editorial Sudamericana. 
Piccinini, M. (2005). Poder común y representación en Thomas Hobbes. En G. Duso (ed.), El Poder: Para una historia de la filosofía política moderna (pp. 98112). Ciudad de México: Siglo XXI Editores.

Rosello, D. (2014). Hobbes y el hombre lobo: devenir animal en (y ante) la soberanía. En M. Figueroa (ed.), Poder y ciudadanía: estudios sobre Hobbes, Foucault, Habermas y Arendt (pp. 11-36). Santiago de Chile: Universidad Adolfo Ibáñez.

Rutheford, R. (2015). Hobbes in moral virtue and the laws of nature. En P. Easton y K. Smith (eds.), The Battle of the Gods and Giants Redux: Central Themes in Early Modern Philosophy. Boston: Brill. DOI: https://doi. org/10.1163/9789004305922_012

Shields, C. (2014). Aristotle. En E. Zalta (ed.), The Stanford Encyclopedia of Philosophy. Stanford: Metaphysics Research Lab, Stanford University. Recuperado de http://plato.stanford.edu/archives/spr2014/entries/aristotle/

Slomp, G. (1990). The significance of glory in the political theory of Thomas Hobbes. (PhD thesis). London School of Economics and Political Science, London, England.

Zarka, Y. (2006). Hobbes y el pensamiento político moderno. Barcelona: Herder. 